\title{
O Trabalho Familiar Extrativista Sob a Influência de Políticas Públicas
}

\author{
Dalva Maria da Mota ${ }^{1}$, Heribert Schmitz² ${ }^{2}$ Josué Francisco da Silva Júnior ${ }^{3}$ \\ e Raquel Fernandes de Araújo Rodrigues ${ }^{4}$
}

Resumo: $\mathrm{O}$ artigo analisa a relação entre a organização do trabalho familiar no extrativismo e a participação em programas de políticas públicas no estado de Sergipe. Com abordagem predominantemente qualitativa, a pesquisa foi realizada com mulheres autodesignadas catadoras de mangaba e marisqueiras, reconhecidas como pertinentes ao segmento dos denominados povos e comunidades tradicionais e afiliadas ao Programa Bolsa Família (PBF), ao Seguro Desemprego do Pescador Artesanal (SDPA) e ao Programa de Aquisição de Alimentos (PAA). A metodologia constou de observações e entrevistas com diferentes atores envolvidos na atividade extrativista e nos programas de políticas públicas. As principais conclusões mostram que os programas de políticas públicas influenciam: i) na reorganização do cotidiano do trabalho no extrativismo, principalmente no tocante à diminuição do envolvimento de crianças e jovens na atividade e quanto à intensidade das jornadas; ii) no reforço aos papéis tradicionais de homens e mulheres, no caso do PBF, e na diluição de fronteiras entre esses mesmos papéis no PAA; iii) na diminuição do volume de trabalho no caso do SDPA e no aumento no PAA; e iv) nos diferentes sentidos que são atribuídos ao trabalho.

Palavras-chaves: Seguro Desemprego do Pescador Artesanal, Programa de Aquisição de Alimentos, Programa Bolsa Família, catadoras de mangaba.

\footnotetext{
Abstract: This paper assesses the relationship between the family labor organization in the extractive activity and the involvement in public policy programs in Sergipe State. The research was predominantly carried out through a qualitative approach with women self-appointed as mangaba gatherers and "marisqueiras". This is a relevant segment to the

1. Doutora em Sociologia, pesquisadora da Embrapa Amazônia Oriental, Belém (PA), bolsista de produtividade do CNPq. E-mail: dalva.mota@embrapa.br

2. Doutor em Sociologia Rural, professor de Sociologia da UFPA, Belém (PA), bolsista de produtividade do CNPq. E-mail: heri@amazonet.com.br

3. Mestre em Fruticultura Tropical; pesquisador da Embrapa Tabuleiros Costeiros; Aracaju (SE). E-mail: josue.francisco@embrapa.br

4. Mestre em Agroecossistemas, analista da Embrapa Tabuleiros Costeiros, em Aracaju (SE). E-mail: raquel.fernandes@embrapa.br
} 
"traditional people and communities" affiliated to the closed season insurance of artisanal fishermen (SDPA), the family grant program (PBF), and the Brazilian food acquisition program (PAA). The research approach included observations and interviews with different social actors involved in the extractive activity and public policy programs. The main findings show that public policies programs: i) influence the reorganization of everyday work in the extractive activity, especially concerning the reduction of the participation of young people and children in the activity and the intensity of working hours; ii) strengthen the traditional roles of men and women in the PBF and dilute the frontiers between these roles through the PAA program; iii) decreases the workload through the SDPA program and increases it in the PAA; and iv) affect the different significances attributed to labor.

Key-words: Closed Season Insurance of Artisanal Fishermen, Food Acquisition Program, Family Grant Program, mangaba gatherer women.

Classificação JEL: J48.

\section{Introdução}

Nas últimas décadas do século $X X$, o capitalismo inicia uma fase de grandes transformações, nas quais emergem novas formas de organização do trabalho ${ }^{5}$ marcadas pela flexibilização no âmbito da reestruturação produtiva (CAVALCANTI, ANDRADE e RODRIGUES, 2012). Em consequência, ao conceito clássico de trabalho associado ao capitalismo moderno na revolução industrial, bastante utilizado para elucidar a relação entre classes no processo de transformação da matéria-prima, agregam-se novas conceituações, a exemplo do"trabalho não clássico" ${ }^{\prime \prime}$ para analisar relações de trabalho em setores não convencionais da economia, a exemplo do trabalho interativo (cuidados de bebês e idosos), trabalho em domicílio (teletrabalho, costureiras etc.) e o setor de serviços em geral (DE LA GARZA, 2013, p. 319).

Nesse contexto de transformações e de predominância da flexibilização, constata-se a

5. Para a conceituação de trabalho, nos orientamos em De La Garza (2000), para quem o trabalho está relacionado com a transformação consciente da natureza e do homem para satisfazer as necessidades humanas. É o meio de criação da riqueza material e imaterial e de fazê-las circular.

6. “Aquele em que a intervenção do cliente é indispensável para que se realize a produção e se tenha o produto. Seja porque se geram símbolos que se transmitem ao cliente ou porque o produto é a interação mesmo" (DE LA GARZA, 2013, p. 319). coexistência de evidências no espaço rural brasileiro associadas à: i) intensificação da precarização do trabalho assalariado na agricultura (CAVALCANTI, ANDRADE e RODRIGUES, 2012; REIGADA, 2014); ii) persistência das formas familiares de produção (PAULILO, 2012) e iii) repressão do trabalho de alguns membros da família nos estabelecimentos familiares (crianças e jovens) em atendimento a diretrizes da Organização Internacional do Trabalho (OIT) e ao condicionamento de alguns programas de políticas públicas nacionais (SARMENTO e STROPASOLAS, 2010). Somam-se a essas tendências as transformações nos modos de organização do trabalho dos produtores de base familiar, que dependem dos recursos naturais para sobreviver, em decorrência do paradoxal papel do Estado na sociedade brasileira que, por um lado, reconhece e apoia aqueles produtores, mas, por outro, promove grandes projetos e apoia iniciativas que ameaçam os seus meios de vida (SHIRAISHI NETO, 2011; BIANCO, 2012; CASTRO, 2012).

Estudos sobre o trabalho familiar no espaço rural têm enfatizado a divisão sexual sob influência da idade e geração e as diferenciações sociais daí decorrentes, reflexos das relações de poder e do acesso aos recursos com o persistente desbalanço entre o reconhecimento do trabalho dos diferentes membros da família. Não obstante, como analisado por Neves e Medeiros (2013, p. 14), 
[...] o trabalho familiar vem incorporando significativas singularidades e pressupondo redefinições na organização de papéis domésticos. No entanto, suas distinções estão muito longe de ser compreendidas, em especial num contexto de reconhecida transformação dos padrões de dominação masculina e de abertura de alternativas de participação econômica e política de homens e mulheres.

No presente artigo, nos propomos contribuir para a compreensão das singularidades do trabalho familiar no extrativismo ${ }^{7}$, atividade que comporta formas tradicionais de trabalho no universo da "tradição mutável mas continuada" (RIBEIRO, 2011, p. 1002) e que tem sido analisado na interface entre "uma identidade, uma história, uma memória partilhada e um território" (ESTERCI, 2007, p. 223).

Interessa-nos analisar a relação entre a organização do trabalho familiar no extrativismo e a participação das extrativistas em programas de políticas públicas no estado de Sergipe. Os sujeitos privilegiados na pesquisa foram as mulheres extrativistas autodesignadas como catadoras de mangaba e marisqueiras ${ }^{8}$, desde que afiliadas exclusiva ou simultaneamente ao Programa Bolsa Família (PBF), ao Seguro Desemprego do Pescador Artesanal (SDPA) e ao Programa de Aquisição de Alimentos (PAA).

O período de pesquisa foi de 2011 a 2014 e a opção pelas mulheres deriva da predominância das mesmas na atividade extrativista vegetal (frutas) aliada à animal (moluscos e crustáceos), bem como pelo papel que protagonizam no trabalho familiar para a manutenção de seus grupos

7. Entendido aqui como a exploração dos recursos naturais (animal e vegetal) em ecossistemas diversos e voltados para diferentes mercados no conjunto de atividades desenvolvidas pelos denominados povos e comunidades tradicionais com baixo impacto ambiental.

8. Autodesignações acionadas, segundo a interlocução, para se fazerem reconhecer em decorrência de referirem-se a atividades que são realizadas complementarmente. Esse movimento é usual no entendimento de muitos autores, que concordam que as identidades não são instâncias fixas, imutáveis ou definitivas, sendo, na maior parte das vezes, situacionais e temporárias (SCHMITZ, MOTA e PEREIRA, 2013). domésticos, trabalho este nem sempre visibilizado. Muito embora usufruam do reconhecimento como sujeito de direitos específicos (a partir da Constituição de 1988) e como um grupo culturalmente diferenciado (Lei Estadual n. 7.082 de 16 de dezembro de 2010), as extrativistas persistem envoltas em processos conflituosos para fazer valer os seus direitos quando se trata do acesso aos recursos, crescentemente ameaçados nos lugares onde vivem (MOTA et al., 2011).

$\mathrm{Na}$ realização da pesquisa, privilegiamos a abordagem qualitativa com uso de entrevistas não diretivas, objetivando conhecer os significados atribuídos pelos sujeitos aos processos que vivenciam. O trabalho de campo foi realizado em localidades costeiras ${ }^{9}$ de Sergipe, nas quais atualizamos contatos preexistentes efetuados por ocasião da realização de uma pesquisa-ação nos anos 2000. Adotamos também o procedimento de uma entrevistada indicar a próxima e, assim, realizamos 50 entrevistas não diretivas com mulheres extrativistas que têm acessado políticas públicas para a redução da pobreza, de fomento à produção e de conservação ambiental e seguridade social instituídos nas últimas décadas.

O artigo está estruturado em quatro partes, quais sejam: i) $\mathrm{O}$ trabalho familiar no extrativismo; ii) políticas públicas em comunidade extrativista; iii) a organização do trabalho sob a influência das políticas públicas e iv) reflexões finais.

\section{O trabalho familiar no extrativismo}

Para a compreensão do trabalho familiar, retomamos a reflexão de Garcia Jr. e Heredia (1971, p. 10) a partir das contribuições de Chayanov. Para os autores, a unidade de trabalho familiar “[...] refere-se ao fato do número de membros e a composição da 'unidade de trabalho' serem arti-

9. Localmente denominados de povoados, onde há um conjunto de ruas, de serviços educacionais e de saúde e uma vida social que gira em torno da intersecção entre as atividades produtivas (extrativismo, turismo e prestação de serviços e assalariamento no turismo), religiosas e de lazer. 
culados por fora das exigências diretas do processo de produção, ou seja, serem dados a priori ao nível do parentesco". Grosso modo, os processos de trabalho são concretizados a partir da divisão sexual do trabalho, condição que influencia na produção de padrões de comportamentos alicerçados numa ordem binária e sexuada que diferencia e hierarquiza o trabalho segundo o sistema sexo/gênero (HEREDIA, 1979; ESMERALDO, 2013).

No extrativismo, análises da organização do trabalho apontam que o trabalho extrativista é feito de acordo com o produto, suas condições de coleta e padrões culturais. A predominância dos homens na atividade, via de regra, está relacionada a disposições culturais e ao valor do produto no mercado. Simonian (2001) analisou que, na Amazônia, os homens geralmente predominam nas atividades extrativistas economicamente mais compensadoras. Não obstante, a autora chama a atenção para a atuação das mulheres no seio da floresta como seringueiras, castanheiras, pescadoras e curandeiras que utilizam os recursos naturais. Na mesma região, mais recentemente, Cruz (2010) ressalta o papel das mulheres e indica que a gama de trabalho por elas realizada não é devidamente valorizado, sendo "considerado tanto pelos homens como pelas próprias mulheres como uma 'ajuda' aos homens: o trabalho produtivo é masculino" (CRUZ, 2010, p. 919).

No litoral de Sergipe, Mota (2005) constatou que a coleta do coco era tradicionalmente realizada por homens, tanto por valores culturais que atestavam que mulheres não devem escalar a planta por pudor, quanto pela maior remuneração do trabalho. A idealização do homem como chefe do grupo doméstico contribui para que os ganhos advindos da venda dos produtos do extrativismo praticado pelas mulheres seja considerado como uma "ajuda" na renda doméstica, mesmo quando essa renda supera aquela aportada pelos homens.

As análises sobre o extrativismo na pesca indicam uma divisão do trabalho bem mais demarcada, na qual aos homens compete a realização da pesca no mar ou no rio e às mulheres, as tare- fas domésticas e a "mariscagem", bem como os trabalhos de beneficiamento e conservação do pescado, a confecção de material de trabalho e a maternagem que implica tanto nos cuidados com crianças e idosos quanto na realização dos trabalhos de higiene das roupas e da casa e preparação de alimentos (MALDONADO, 1986; ALENCAR, 2013; MANESCHY, 2013).

As atividades produtivas femininas, em sua maior parte, são descontínuas e nem sempre se traduzem em renda monetária, o que contribui para reforçar sua invisibilidade e dificultar o surgimento de uma "consciência profissional" das trabalhadoras da pesca (MANESCHY, 2013, p. 45).

Tratando-se da organização do trabalho tanto no extrativismo vegetal quanto no animal, tradicionalmente o trabalho está organizado segundo laços de parentesco influenciados por noções de gênero, idade e geração. Em respeito a essas noções, se estruturava a socialização para o trabalho de filhos e filhas, desde a mais tenra idade por meio da iniciação ocupacional conferida pelos pais nos seus respectivos espaços de atuação (SILVA, 2004).

Qualquer que seja o tipo de extrativismo (animal ou vegetal), constatamos uma tendência de associação entre compensação financeira (preço alcançado nos mercados locais), perigo (violência, assombrações, mistérios) e gênero.

O extrativismo praticado pelas mulheres no litoral de Sergipe situa-se em arranjos postos em prática pelas famílias para garantir o seu aprovisionamento e dependem do seu ciclo de reprodução - expansão, dispersão ou substituição - (FORTES, 1974), do cálculo econômico do necessário à reprodução social (consequentemente, do acordo ou não dos seus membros em realizarem dadas tarefas), da sazonalidade peculiar à atividade extrativista, do acesso aos recursos e da reprodução social e cultural do grupo, como observado em diferentes estudos de caso realizados em Sergipe, nos quais as mulheres e suas famílias têm acesso comum ou privado aos recursos (MOTA, SILVA JÚNIOR, SCHMITZ e RODRIGUES, 2011; SANTOS, 2007; PEREIRA, 2008). 
Em todos os casos, na divisão sexual do trabalho praticada no extrativismo (à exceção do alto mar), sobressai a predominância do trabalho das mulheres em conciliação com o trabalho doméstico. A elas compete tornar possível o processo de trabalho com a "ajuda" de outros membros da família. O envolvimento dos filhos, entretanto, depende de arranjos conformados pelo tipo de atividade e pelos horários de frequência deles à escola. Compete a elas tomar decisões relativas às atividades de pós-coleta e de comercialização em diálogo com outras estratégias familiares que implicam na disposição dos seus membros num ou noutro lugar. As atividades são combinadas com aquela dos homens que praticam o extrativismo animal em alto mar de modo que as funções primordiais da família sejam mantidas em processos que garantam a sobrevivência e a socialização.

Mais recentemente, entretanto, o ritmo das atividades tem sido influenciado pela crescente devastação dos recursos para a instalação de viveiros de camarão, agricultura e construção de infraestruturas turísticas. Nesse contexto, o aporte de outras rendas via programas de políticas públicas interfere tanto na relação com os recursos naturais, quanto na organização do trabalho da mulher e de outros membros da família.

\section{Políticas públicas em comunidade extrativista}

O PBF, o SDPA e o PAA têm sido bastante analisados na literatura no Brasil (SILIPRANDI e CINTRÃO, 2011; REGO e PINZANI, 2013a; SCHERER, 2013), especialmente com relação às suas repercussões entre os agricultores familiares e pescadores artesanais. As análises escasseiam quando se trata de grupos de mulheres que não têm acesso à terra e dispõem de modo irregular dos recursos naturais para o exercício da coleta vegetal em terras devolutas e de terceiros e do extrativismo animal nos manguezais.

\subsection{Os programas $P B F, S D P A$ e $P A A$}

Observadas a partir das suas condições de aprovisionamento, de acesso a serviços e aos recursos dos quais dependem para sobreviver, as mulheres extrativistas, grosso modo, correspondem a um dos grupos sociais mais vulneráveis da sociedade brasileira e, por este motivo, têm sido beneficiárias dos programas de transferência de renda e de fomento a produção no âmbito do Programa Brasil Sem Miséria (PBSM) que abriga tanto o PBF quanto o PAA.

Concordamos com Rego e Pinzani (2013a, p. 213), no que se refere ao fato de que o PBF "pode ser visto como uma política de urgência moral, capaz de estabelecer as condições mínimas para o desenvolvimento de autonomia ética e política". Argumentam os autores que "a condição de indigência e de falta de independência econômica se traduz na sensação de que a própria personalidade permanece incompleta, inacabada, por assim dizer" (REGO e PINZANI, 2013a, p. 219) e, portanto, amordaçada quanto às iniciativas que permitem o desenvolvimento das capacidades.

As reflexões dos autores têm correspondência na fala das entrevistadas que, a partir do aporte do PBF, reconstroem os seus discursos e incorporam o valor da autonomia:

Não é só por causa do dinheiro, mas a gente se anima, hoje mesmo estava falando que posso planejar comprar algo porque tenho minha Bolsa e vou pagar. Se eu precisar de uma cama, pra mim ou meu filho, sei que posso ir até a loja e comprar, isso que eu faço (J. P. S. 35 anos, catadora de mangaba e marisqueira).

$\mathrm{Na}$ minha vida ele [PBF] é extremamente importante, porque se não fosse esse dinheiro, não teria condições de deixar [nome do filho] estudando pela tarde e eu sozinha trabalhando. Quando eles precisam de um material de escola, já tem o dinheiro que ajuda a comprar. Se fosse só do meu trabalho não teria como! (E. M. S., 30 anos, marisqueira). 
Das entrevistadas, 75\% têm acesso ao PBF. É a modalidade mais conhecida e mais procurada pelas mulheres extrativistas entrevistadas que, em sua grande maioria, acessa-a regularmente desde a sua institucionalização em 2004. O PBF unificou diversos programas sociais até então vigentes. É um programa de transferência direta de renda com condicionalidades voltadas aos cuidados com as crianças, jovens, gestantes e nutrizes. Seu objetivo é a superação da situação de vulnerabilidade da população que se encontra na pobreza (renda mensal por pessoa entre R $\$ 77,01$ e R $\$ 154,00$ ) e na extrema pobreza (renda mensal por pessoa de até $\mathrm{R} \$ 77,00)$, mediante a promoção de segurança alimentar e cidadania. Em junho de 2014, o PBF beneficiava mais de 14,2 milhões de famílias no Brasil (MDS, 2014a). Em Sergipe, nesse mesmo período, foram beneficiadas 285.529 famílias.

Para fazer parte da seleção de beneficiários de programas sociais do governo federal, inclusive o PBF, as famílias devem estar obrigatoriamente inscritas no Cadastro Único (CadÚnico), no qual constam informações das características do domicílio, das formas de acesso a serviços públicos essenciais, dados de cada um dos componentes da família e, também, se fazem parte de povos e comunidades tradicionais indígenas, extrativistas, quilombolas etc.) ou de população em situação de rua. Além de estabelecer canais que possibilitem aos interessados solicitar sua inscrição no CadÚnico, o governo tem adotado a estratégia de "busca ativa", ou seja, a criação de equipes volantes responsáveis em encontrar e cadastrar famílias pobres e extremamente pobres. De acordo com a composição e renda per capita identificadas no CadÚnico, as famílias se tornam aptas a receberem benefícios do PBF, cujo valor médio é de R\$169,41 no Brasil e R\$161,08 em Sergipe (MDS, 2014b).

Ainda no escopo do PBSM, o PAA notabiliza-se por atentar para a comercialização e distribuição da produção. Segundo Delgado, Conceição e Oliveira (2005), o objetivo do PAA é "[...] garantir o acesso aos alimentos em quantidade, qualidade e regularidade necessárias às populações em situ- ação de insegurança alimentar e nutricional e promover a inclusão social no campo por meio do fortalecimento da agricultura familiar". Os autores indicam que, com essa finalidade, apoia-se simultaneamente a compra e venda de alimentos dos agricultores familiares e incentiva a participação nos circuitos formais de comercialização, visando a estimular a produção de alimentos na agricultura familiar e permitir a comercialização no mercado institucional.

Mais do que isso, representa "a simbiose entre política agrícola e política social" (DELGADO, 2013 , p. 6). Acumulando intensa e competente dedicação à avaliação do PAA, o autor afirma que:

\begin{abstract}
Nesse sentido, cumpriu um virtuoso papel de desenvolvimento rural, qual seja, o de induzir a elevação do excedente econômico dos produtores familiares de alimentos mediante ação estrita de garantia de comercialização e de fortalecimento de suas organizações associativas (DELGADO, 2013, p. 6).
\end{abstract}

Dentre as mulheres extrativistas entrevistadas, cerca de $50 \%$ participaram do PAA no período de 2006 a 2010, quando o programa foi interrompido na localidade. As explicações para a interrupção, para uns, foi decorrente de problemas operacionais do próprio programa, para outros, foi ocasionado pela qualidade dos frutos.

Qualquer que seja a compreensão, há unanimidade quanto à importância do PAA na dinamização da economia local e na melhoria das condições de vida. Sobre as vantagens de participação no PAA, uma extrativista relatou:

Não se submeter a vender num preço mínimo quando tem muita mangaba. Não perde mais a mangaba. E antigamente os compradores de fora não levavam as maduras e eu perdia Quando cata mangaba deixa todos os afazeres extras, como mangue, tarefas domésticas. Deixa de fazer as coisas para ir catar mangaba (S. A. S., 35 anos, catadora de mangaba e marisqueira).

Ademais, o PAA influenciou no reconhecimento e valorização do trabalho extrativista e 
para o incentivo à diversificação do consumo de alimentos associados a locais e épocas. As dificuldades que permearam a experiência referem-se ao problema de compreensão da burocracia e do funcionamento do programa.

Em 2013, no estado de Sergipe, as operações do PAA se deram em apenas seis municípios e envolveram recursos advindos do Ministério do Desenvolvimento Agrário (MDA) e do Ministério do Desenvolvimento Social e Combate à Fome (MDS), da ordem de R\$1,4 milhão, nas modalidades Compra com Doação Simultânea (CDS), Compra Direta da Agricultura Familiar (CDAF) e Apoio à Formação de Estoque pela Agricultura Familiar (CPR-Estoque), todas operacionalizadas pela Companhia Nacional de Abastecimento (Conab). Foram adquiridas 748 toneladas de produtos fornecidos por 288 beneficiários, sendo categorizados pela Conab em 225 agricultores familiares e 63 assentados (CONAB, 2013). Em Sergipe, a participação das mulheres no PAA cresceu notavelmente, passando de $25,0 \%$, em 2009, para $40,3 \%$, em 2012 (CONAB, 2014).

Tratando-se especificamente da mangaba, fruta coletada pelas extrativistas aqui em análise, o estado de Sergipe foi o responsável por $72 \%$ do volume adquirido na forma de polpa congelada e de fruta fresca, de acordo com a Gerência de Acompanhamento e Controle das Ações da Agricultura Familiar (Gecaf) da Conab, entre 2010 e junho de 2014.

O SDPA, diferente do PBF e do PAA, é um direito definido a partir da inclusão plena dos trabalhadores rurais no sistema previdenciário oficial, o que ocorreu com a promulgação da Lei n. 8.213, de 25 de julho 1991, que incluiu os pescadores artesanais entre os segurados especiais: aqueles que, "individualmente ou em regime familiar", fazem da pesca sua "profissão habitual ou principal meio de vida", desde que respeitadas algumas outras características (LOURENÇO, HENKEL e MANESCHY, 2006). Também passam a ser possíveis segurados especiais o cônjuge e os filhos maiores de 16 anos de idade, desde que comprovem o exercício da atividade.
De acordo com Moreira e Scherer (2013), no ano de 1991 foi promulgada a Lei n. 8.287 "que concede aos pescadores artesanais os benefícios do seguro desemprego na época de defeso". Essa política que instituiu o seguro desemprego está intrinsecamente ligada à que culminou com a equiparação dos direitos de trabalhadores rurais aos dos trabalhadores urbanos, obtida a partir da Constituição de 1988, na qual “os pescadores artesanais conquistaram avanços no que tange aos direitos sociais e políticos, quando as colônias de pescadores, através do artigo $8^{\circ}$, foram equiparadas aos sindicatos de trabalhadores rurais, recebendo a configuração sindical" (MORAES, 2001, p. 1). Tais políticas estenderam aos trabalhadores rurais benefícios sociais, como: aposentadoria, auxílio-maternidade, auxílio-doença e auxílio acidente de trabalho, os quais eram, em princípio, exclusividade dos trabalhadores urbanos assalariados (TEIXEIRA e ABDALLAH, 2008).

Com as novas conquistas sociopolíticas no setor pesqueiro, os pescadores artesanais ganham visibilidade como "[...] sujeitos sociais e reconhecimento como sujeitos portadores de direitos" (MOREIRA e SCHERER, 2013). De acordo com essas mesmas autoras, tais processos sociojurídicos e as articulações políticas em curso vêm provocando transformações no mundo da pesca, ressignificando identidades, acendendo mudanças nas consciências e nos comportamentos para com os ambientes pesqueiros, reconhecendo o trabalho das mulheres nesse setor e provocando a organização dos trabalhadores para a regularização da documentação.

No período de 2011 até março de 2014, o governo federal disponibilizou $\mathrm{R} \$$ 6,15 bilhões para o pagamento do SDPA aos pescadores artesanais do País. O estado de Sergipe recebeu R\$ 176 milhões, distribuídos para 28.249 beneficiários, em 57 dos 75 municípios do seu território, constituindo-se no sexto mais favorecido, atrás do Amazonas, Bahia, Piauí, Maranhão e Pará. Os municípios com maior número de beneficiários foram São Cristóvão (2.461), Pirambu (2.168) e Aracaju (2.081). 
Dentre as mulheres entrevistadas, $70 \%$ são afiliadas ao SDPA e as demais explicitam o desejo de terem acesso ao mesmo. Para uma entrevistada, as razões do SDPA podem ser assim explicadas:

$\mathrm{Eu}$ acho [criaram o SDPA] pra reconhecer mais o pescador, porque quem pesca precisa, tem pescaria que dá e tem pescaria que não dá dinheiro. Acho que agora tem menos, os peixes são assim, tem maré que dá e maré que não dá, ostra, a gente se bate muito, a gente vai em 2, 3 mangue pra poder pegar ostra e quase não acha. [...]. Pra nós é essa ajuda de custo que entra pra família da gente (J. P. S. 35 anos, catadora de mangaba e marisqueira).

\subsection{Os diferentes modos de acesso ao PBF, SDPA e PAA}

Analisados comparativamente, o PBF é o programa ao qual mais facilmente as mulheres extrativistas tiveram acesso. Segundo informam, elas tomaram conhecimento do PBF por meio de propaganda em carros de som, programas de rádio locais, agentes de saúde e vizinhas. Apenas 6,6\% das entrevistadas declararam problemas com a inscrição, tendo que ir mais de uma vez ao local de cadastramento para passar a receber o recurso.

Em relação ao SDPA, a divulgação do programa foi decorrente do contato pessoal com os presidentes das colônias de pescadores e com as vizinhas que já tinham o benefício. Diferente das demais afiliações, a participação no PAA se deu em 2006, para a comercialização exclusiva de frutas oriundas do extrativismo após um trabalho intenso de divulgação de uma liderança regional, dirigente de uma cooperativa de assentados da região sul de Sergipe. Assim, foi a primeira experiência de extrativistas de mangaba no PAA no Brasil.

Depois de algumas reuniões, um pequeno número de mulheres extrativistas se afiliou, enfrentando a desconfiança das demais que temiam a nova experiência por medo de atraso dos recursos. Elas estavam também temerosas de romper compromissos com intermediários com os quais mantinham vínculos não estrita- mente de comercialização, mas também de amizade e dependência. Posteriormente, após o recebimento do dinheiro pelas afiliadas, houve uma corrida das demais na tentativa de afiliação, entretanto elas esbarraram nas dificuldades para a obtenção da Declaração de Aptidão ao Pronaf (DAP) pela insuficiência de documentos ou pela falta de recursos para os deslocamentos para a sede municipal, onde a DAP é processada. Mesmo assim, redes usuais de solidariedade foram ativadas e aquelas oficialmente cadastradas acolheram a produção das outras e depois dividiram o dinheiro correspondente.

No âmbito institucional, todas as mulheres entrevistadas reconhecem que o SDPA é a política mais difícil de ser acessada porque consideram complicado corresponder às exigências documentais e nem sempre entendem a atribuição exata das diferentes instituições que lidam com o benefício. Idas e vindas numerosas conformam os processos de afiliação e, em alguns casos, mulheres tentam acessar, sem sucesso, há seis, sete anos.

No caso do PAA e do SDPA, existe a insuficiência de informação quanto aos documentos e à incompreensão dos processos inerentes a cada programa, como também o desconhecimento das regras. Entretanto, elas explicitam conhecer muito bem o seu funcionamento local. Os referidos problemas ocorrem em menor escala no PBF. A universalização do direito e a alta frequência dos que têm direito ao mesmo parecem ter proporcionado uma aprendizagem social que beneficia essas mulheres.

Os diferentes modos de divulgação dos programas localmente imprimiram determinada tendência na seleção prévia das mulheres consideradas aptas ao SDPA (ter afinidades pessoais, ser marisqueira) e PAA (ser catadora de mangaba e assim reconhecida). No caso do SDPA, o acesso através de laços de pessoalidade construída, principalmente, em torno do dirigente da colônia dos pescadores, pode representar uma facilidade. Entretanto, isso não tem impedido o cadastro das demais no programa, o que mostra o potencial das redes de interconhecimento e vizinhança na influência de todas as afiliações. 
As três políticas públicas, ao mesmo tempo em que são acionadas pelas relações primárias, ensinam novas formas de se relacionar, ultrapassando as barreiras da vizinhança e construindo a interação com as instituições. Esse processo é essencial na busca de maiores conquistas, tal como indicam Hébette et al. (2002), em estudo sobre um grupo de camponeses na Amazônia que, por meio da influência da Igreja Católica, construíram espaços de caráter público (capelas e roças comunitárias), que desencadearam a formação de importantes organizações mobilizadas para o alcance de direitos.

Comparando-se os modos de acesso aos diferentes programas e beneficio, constatamos que, por um lado, o PBF, o SDPA e o PAA foram acessados a partir de um apelo institucional que incentivou o envolvimento das mulheres no universo da burocracia, pouco conhecido por elas. Por outro lado, as dificuldades vivenciadas são interpretadas como um processo de aprendizado e socialização que influenciou para que as mulheres extrativistas entrassem "no mundo da documentação", condição indispensável para uma existência cível (MOREIRA e SCHERER, 2013, p. 149).

\section{A organização do trabalho familiar no extrativismo sob a influência dos programas de políticas públicas}

\subsection{Transformações nos processos de trabalho}

O PBF, o SDPA e o PAA influenciam significativamente na organização do trabalho familiar no extrativismo vegetal e animal na região litorânea de Sergipe, particularmente quanto ao processo de coleta e comercialização dos produtos e aos papéis desempenhados pelos diferentes membros dos grupos domésticos. Interferem, assim, na quantidade de trabalho depreendido nas atividades e na configuração de novas dinâmicas sociais locais, as quais extrapolam o campo da produção em consonância com os propósitos das mulheres extrativistas.

No caso do PAA, a possibilidade de venda regular da mangaba a preço justo levou à inten- sificação da jornada de trabalho, com o envolvimento não usual de outros membros do grupo doméstico (companheiros, esposos) e até mesmo de grupos de parentes no processo de coleta e beneficiamento dos frutos. A busca por novas áreas de acesso livre para a coleta e o estabelecimento de acordos com proprietários de terra que têm mangabeiras em suas áreas evidenciaram-se como estratégias que permitiram a intensificação do trabalho e a obtenção de maior volume de frutos. Além disso, ocorreu um aumento do número de idas aos campos e da diversificação dos horários, além da ampliação do número de catadoras num contexto de redução dos recursos (corte das plantas e privatização por meio de cercas).

Até o advento do PAA, o extrativismo de mangaba era exclusividade das mulheres em Sergipe, sendo discriminados os homens que porventura o praticassem porque "não é trabalho de homem", questionando-o enquanto trabalho apropriado ao modelo ideal do que seria um provedor naquele contexto. Em outros estados do Brasil, como na Paraíba, Tocantins e Minas Gerais, constatamos que os homens participam ativamente da coleta e, em alguns casos, a monopolizam.

Para além da intensidade do trabalho na coleta e no beneficiamento dos frutos, mudanças importantes foram observadas na dinâmica de mercado e na organização do trabalho para concretizar a participação das mulheres extrativistas no PAA. Em termos de mercado, houve a diminuição da comercialização nas feiras e nos próprios povoados por meio dos intermediários pela comercialização associativa, via organizações e através de lideranças locais. Com isso, houve a redefinição da relação com os intermediários, mas sem rupturas porque são constituídas de relações não estritamente econômicas.

A concretização da participação das mulheres extrativistas no PAA, por sua vez, demandou importante volume de trabalho das lideranças que tanto cuidaram da parte burocrática quanto da operacionalização das entregas dos frutos, o que exige pesar, anotar e organizar o transporte para as instituições receptoras. Essas últimas atividades ficaram concentradas nas mãos de duas 
lideranças que passaram a exercer funções anteriormente inexistentes, sem remuneração, e aprenderam a lidar com os processos burocráticos no âmbito do PAA. Ademais, elas adentraram em redes institucionais que as credenciaram a persistir no debate sobre o programa e nas tentativas de novas participações.

Diferente do PAA, que estimula a ação das mulheres extrativistas na coleta vegetal, o PBF está mais associado à sua presença na esfera privada, no qual as ações afetas à reprodução do grupo doméstico têm maior relevância em decorrência das condicionalidades do programa. Como reconhecem as mulheres extrativistas, a manutenção das crianças na escola é condição essencial para persistirem como beneficiárias. Para efetivá-las, afirmam se dedicar com mais intensidade às tarefas domésticas como preparação de alimentos, fardas e acompanhamento das crianças que frequentam a escola. A maior presença na residência acarreta mudanças nos modos de socialização de crianças e jovens no mundo do trabalho em decorrência das suas iniciações serem para muitas atividades incentivadas pelas mães. O evento vem sendo reforçado por outros programas, como o Programa de Erradicação do Trabalho Infantil (PETI).

As transformações ocasionadas no processo de trabalho são bem marcantes quando analisado o extrativismo animal praticado pelas mulheres no manguezal. Diferente do PAA, que incentiva a disponibilidade de maior volume de frutos para a comercialização, o incentivo do SDPA é a paralisação da atividade de coleta no transcorrer da reprodução de determinada espécie (camarão na região sul de Sergipe). O volume de recursos financeiros recebidos é superior aos demais e, assim, as extrativistas afirmam que investem em barcos e equipamentos para praticar a coleta com mais eficiência. Para além da facilidade de deslocamento nas diferentes "marés", o barco possibilita chegar a manguezais mais distantes considerando-se que aqueles mais facilmente acessíveis estão superexplorados, particularmente após a instalação de viveiros de camarão (SCHMITZ, MOTA e PEREIRA, 2013).
Assim, há indicativos de que os recursos aportados pelo SDPA influenciam no processo de trabalho, tanto pelo uso de novos equipamentos quanto pela relação com o tempo, uma vez que o SDPA indica quando é permitido e proibido pescar. A despeito da melhoria do processo de trabalho, há um debate local quanto à efetividade do SDPA na inibição da atividade, porque, no dia a dia, o exercício das atividades é mais condicionado ao atendimento das necessidades da família do que ao cumprimento da exigência legal.

Comparando-se o PBF, o SDPA e o PAA em relação ao trabalho extrativista, constatamos que as orientações são diferentes e complementares. Enquanto um incentiva o trabalho produtivo, o outro privilegia o reprodutivo e o outro alia a produção com a conservação ambiental. As intepretações realizadas pelas mulheres extrativistas localmente desaguam em arranjos que permitam maximizar as suas participações em mais de um. Assim, reinventam os processos de trabalho com horários e envolvimento de terceiros, como constatado no caso do PAA e do SDPA, e ainda cumprem o papel de mãe, esperado no PBF.

\subsection{Divisão sexual do trabalho: quem e quando trabalha?}

No padrão tradicional de organização do trabalho no extrativismo vegetal e animal no litoral sul de Sergipe, persiste a identificação de espaços associados às mulheres e aos homens. Noções de complementaridade, oposição e concorrência permeiam as relações que, sob as influências recentes de programas de políticas públicas, adquirem novos sentidos que implicam na ressignificação dos papéis. Assim, entra em questionamento a intensidade da socialização das filhas nos espaços de trabalho considerados correlatos às mulheres, como o manguezal (extrativismo animal) e as áreas de coleta de frutas; e dos filhos, nos espaços de realização da pesca.

Em relação aos programas em análise, as influências dos mesmos na divisão do trabalho têm destaque no caso do PAA, porque, mediante o preço justo pago pelos frutos oriundos do 
extrativismo, as mulheres foram valorizadas e os homens direcionaram a sua atenção para a atividade.

Para as mulheres extrativistas em Sergipe, o extrativismo é considerado um campo de domínio delas, do mesmo modo que a pesca em alto mar e a colheita do coco são de domínio dos homens. Assim, existe a noção de "nem fica bem um homem se abaixando para pegar mangaba", considerada uma atividade que não garantia o aprovisionamento do grupo doméstico. Essa noção, entretanto, foi posta em questionamento no decorrer do funcionamento do PAA, devido à obtenção de preços justos e à possibilidade de auferir mais lucro por meio de uma maior quantidade comercializada. Assim, houve a revisão do papel dos homens que, embora ainda na condição de "ajuda", participaram dos processos de coleta e beneficiamento dos frutos oriundos do extrativismo.

Mesmo que localmente o envolvimento dos homens tenha sido considerado uma novidade, pesquisadores mostram que os papéis dos homens e mulheres podem ser redimensionados quando a renda se torna um atrativo, conforme indicamos anteriormente neste mesmo artigo.

Em outra escala, observamos que novos tipos de trabalho não existentes entre as extrativistas foram instituídos a partir do funcionamento do PAA localmente, a exemplo da organização dos eventos de entrega e da contabilidade dos frutos comercializados por cada uma das mulheres extrativistas. Nesses casos, compensações que não são financeiras balizam as suas práticas.

Comparativamente, o PBF e o PAA influenciam na maior presença da mulher na casa e nas áreas de coleta, respectivamente. Assim, reforçam-se novos e tradicionais papéis.

Em relação às crianças, predomina o incentivo ao estudo em detrimento do trabalho e, em decorrência disso, elas são cada vez mais desvinculadas da socialização para o trabalho nos moldes vivenciados pelas suas mães e pais. Ocasionalmente, entretanto, elas participam do extrativismo porque persiste a noção quanto à importância de usufruir dos recursos advindos do seu próprio trabalho. Assim, é frequente a afirmação de que "ele precisava de um sapato e foi comigo pegar mangaba". Nesse sentido, atributos de socialização são conferidos a esses eventos pela possibilidade de aprendizado de um ofício, mas também de códigos morais e hierarquias (NEVES, 1999).

No que concerne ao SDPA, não constatamos que o padrão traçado localmente quanto ao trabalho de homens na pesca e de mulheres no manguezal tenha sido alterado. Entretanto, as condições de trabalho mudaram com a aquisição de novos equipamentos, e as mulheres usufruem, segundo informam, de novas possibilidades em relação ao tempo em que não podem "mariscar":

A gente da pesca sabe, porque se a gente vai e pega os bichinhos no período da desova deles, como é que vai ter mais? Inclusive o aratu que é o que a gente pesca mais, tem épocas que as fêmeas estão cheias de ovas, e nessa época a gente tem que evitar, não pode pescar elas (J.P.S., catadora de mangaba e marisqueira, 35 anos).

Ser incentivada a se dedicar aos cuidados que permitem a frequência dos filhos à escola, paralelamente ao incentivo da participação em canais mais justos de comercialização dos frutos do extrativismo vegetal e à paralisação remunerada das atividades na época da desova das espécies, conformam as condições mínimas de bem-estar material para uma qualidade de vida cidadã que, por sua vez, influenciam nos sentidos atribuídos ao trabalho.

\subsection{Sentidos atribuídos ao trabalho}

A afiliação aos programas PBF e PAA e o acesso ao direito via SDPA influenciam na conformação de diferentes sentidos sobre o trabalho. A afiliação ao PBF revalorizou o trabalho doméstico na esfera da reprodução e pôs em questionamento o trabalho externo dos pais, realizado anteriormente, a qualquer preço para manter os filhos. Nas palavras de uma entrevistada, "agora não saio mais doida por aí para arranjar comida para dentro de casa". Em estudos sobre os impactos do PBF, Rego e Pinzani (2013b) classificaram 
essa luta diária por alimentos de "caçar comida", apontando a renda estável oriunda do PBF como "condição real de início de processos de libertação", a exemplo de aprender a lidar com um planejamento financeiro familiar mínimo ou da ampliação do seu raio de circulação e acesso aos serviços (agências bancárias, secretarias municipais, supermercados, lojas diversas etc.).

Sob outro olhar, recolocou as crianças, habituais consumidoras, na condição de um tipo de "provedora", porque frequentemente as mulheres apontam que a fonte do recurso são as crianças e, como tal, elas merecem algo diferenciado, como um presente a cada recebimento do dinheiro. Provavelmente, na história do grupo, o trabalho dos adultos esteja sendo pela primeira vez protegido (no sentido de não se submeter a qualquer condição). Assim, há uma valorização diferenciada, não pelo que se faz, mas pelo que se faria para ter dinheiro para comer.

A participação no PAA foi condicionada ao trabalho. Auferiu rendimentos a quem comercializou uma quantidade de frutos proveniente do seu próprio esforço. Há, desse modo, a evidência do valor do trabalho tanto pelo preço considerado justo quanto pelo reconhecimento social da importância da participação. As mulheres extrativistas explicitaram que, no PAA, quanto mais se "trabalha na coleta, mais se ganha em recursos financeiros e em autonomia na comercialização". A ressignificação do trabalho ocorre também quando este deixa de ser pensado apenas como meio de garantia das necessidades materiais e passa a ser visto também como criador de laços sociais e confiança, como constatado no caso do PAA.

Os sentidos do trabalho, no caso especifico do SDPA, foram evidenciados com uma certa ambiguidade. Para uns, é uma ajuda para os pobres. Para outros, é um programa para proteger determinadas espécies no momento da desova. Em nenhum caso, escutamos algo relacionado à sobrevivência dos que têm que parar de trabalhar em decorrência da reprodução das espécies. Essas compreensões nos permitem pensar que o sentido do trabalho e do reconhecimento de determinada categoria socioprofissional vinculam-se à uma valorização interna (no local pelos familiares e vizinhos) e externa (pelo estado, oficial).

No geral, participar de cada um dos programas implica num volume maior de trabalho para as mulheres pelo redimensionamento da participação de crianças e adolescentes e pela intensificação das jornadas, à exceção do SDPA. Entretanto, o encargo veio acompanhado do reconhecimento, do valor do trabalho e da conquista de maior autonomia, condição essencial na construção da garantia da própria sobrevivência e dos seus dependentes (REGO e PINZANI, 2013a).

\section{Reflexões finais}

O objetivo do artigo foi analisar a relação entre a organização do trabalho familiar e a participação em programas de políticas públicas no extrativismo no litoral do estado de Sergipe. Tratamos de mulheres extrativistas, autodesignadas catadoras de mangaba e marisqueiras afiliadas ao Programa Bolsa Família (PBF); Seguro Desemprego do Pescador Artesanal (SDPA) e ao Programa de Aquisição de Alimentos (PAA) sob a perspectiva do trabalho familiar realizado no extrativismo vegetal e animal na região litorânea de Sergipe.

As mulheres extrativistas constituem um grupo culturalmente diferenciado que apenas recentemente goza do reconhecimento oficial do Estado como sujeitos de direitos específicos. Constatamos que foi no decorrer dos anos 2000 que ocorreram as afiliações aos programas em análise, sendo que o PBF inova no sentido de garantir as condições mínimas de sobrevivência; o SDPA é o precursor em relação à seguridade social direcionada a um segmento profissional rural específico; e o PAA, frente à comercialização de um produto oriundo do extrativismo praticado predominantemente por mulheres.

No que diz respeito às afiliações ao SDPA, as mulheres extrativistas dependem do reconhecimento como pescadoras pelas colônias de pescadores, ambientes masculinos e sob fortes interesses políticos. O PAA exige a participação 
em uma rede operacional e de condições que independem da extrativista (abertura de editais, elaboração de projetos, obtenção de DAP, interesse das organizações locais, trabalho voluntário das lideranças, disponibilidade do recurso na esfera federal etc.). O PBF, em comparação com os outros programas, é mais objetivo e normativo porque indica a renda per capita e inscrição no CadÚnico de fácil comprovação (carteira de identidade, cartão de vacinação, acompanhamento pré-natal, certidão de nascimento, frequência escolar).

Enquanto a abrangência direta do PAA e do SBPA é o meio rural, o PBF alcança um maior número de pessoas, pois é um programa voltado para pobres ou extremamente pobres do meio urbano e rural. De modo geral, a sociedade civil acompanha e controla mais o PBF do que os demais, talvez porque é mais difundido e, assim, é dele que se tem mais conhecimento, o que melhora o funcionamento do PBF pela aprendizagem social.

Quanto à organização do trabalho, constatamos que o PBF, o SDPA e o PAA influenciam, cada um ao seu modo, na reorganização do cotidiano do trabalho, no extrativismo. O PBF reforça a maior presença das mulheres na esfera doméstica e, com isso, diminui a vulnerabilidade delas para ofertar mão de obra quase gratuita no mercado de trabalho. Ademais, contribui para reduzir a pressão sobre os recursos naturais, anteriormente a principal fonte de proteína animal do grupo doméstico (caranguejos e mariscos coletados no manguezal). No que diz respeito ao trabalho dos diferentes membros da família, o PBF contribui para diminuir significativamente a participação das crianças e jovens no extrativismo porque elas têm que estudar no dia a dia, uma das condições para continuar tendo acesso ao programa. Assim, o padrão de socialização para o trabalho no extrativismo sofre transformações e as crianças e jovens o praticam menos frequentemente.

Por sua vez, os recursos aportados pelo SDPA e as orientações veiculadas quanto ao mesmo influenciam no aperfeiçoamento do processo de trabalho porque facilitaram a compra de equi- pamentos que permitem praticar o extrativismo animal em lugares mais conservados, geralmente distantes; ou seja: "onde tem melhores mangues". O trabalho, do mesmo modo que no PBF, tem se concentrado nas mãos dos adultos. É muito tênue entre os afiliados a noção de que o SDPA é um direito e que a sua orientação relaciona-se mais à conservação dos recursos naturais e à sobrevivência do grupo do que à de potencialização do trabalho.

Diferente do PBF e do SDPA, o PAA incidiu fortemente nos processos de trabalho, estimulando a intensificação da jornada e do volume coletado de frutos. Ademais, diluiu a divisão sexual do trabalho, contribuindo para romper com a noção de que homem não deve trabalhar com mangaba. No auge do funcionamento do PAA, mulheres, homens, jovens e crianças se envolveram fortemente na coleta para aumentar a quantidade de frutos por grupo doméstico.

Comparativamente, concluímos que os programas em análise estimulam diferentes arranjos em relação à organização do trabalho familiar. Por conseguinte, as interpretações e práticas dos atores localmente se inovam. Em linhas gerais, constatamos a diminuição do envolvimento das crianças e jovens nas atividades produtivas; o reforço aos papéis tradicionais de homens e mulheres no caso do PBF e à diluição de fronteiras entre esses mesmos papéis no PAA; a diminuição do volume de trabalho no caso do SDPA e o aumento no PAA; o maior reconhecimento oficial do papel das catadoras de mangaba e marisqueiras; e a conformação de diferentes sentidos atribuídos ao trabalho com o reforço ou desestímulo a posições tradicionais.

As apreciações quanto ao PBF, ao SDPA e ao PAA variam segundo as afiliações, sendo, em geral, muito positivas para quem tem acesso aos mesmos ou pretende acessá-los. Entretanto, as críticas negativas permeiam os discursos daqueles que não os acessam, quer seja por não serem elegíveis, quer seja por não conseguirem em razão da insuficiência de documentos.

As apreciações sobre o PAA valorizam tanto a venda a preço justo como o conteúdo em si do 
programa, associado à valorização do trabalho e à visibilidade das mulheres extrativistas catadoras de mangaba.

As observações sobre o SDPA e o PBF oscilam entre direito, dever do Estado e doação. Em relação ao SDPA, as críticas recaem sobre a seleção das afiliadas, porque para algumas mulheres é injusto que pessoas que não vão para o manguezal tenham direito:

porque muita gente que vai pro mangue não tem direito, e outras pessoas que não vão pro mangue tiram [o Seguro-desemprego] (G. T. catadora de mangaba, 20 anos).

Retomamos uma situação de campo quanto às diferentes apreciações do PBF. Em três entrevistas, catadoras de mangaba que não são beneficiárias do PBF, incentivadas a explicitar os efeitos do program,a afirmaram que "deixa é o povo preguiçoso, porque tem gente que deixa de trabalhar pra receber essa Bolsa". "O povo está fazendo mais filho por causa dessa Bolsa Família". Apesar das afirmações, elas não conseguiram apontar nenhuma família que exemplificasse essa situação. Quando essa possibilidade de "efeito preguiça" e aumento proposital do número de filhos foi por nós colocada para uma beneficiária do PBF, ela recebeu a notícia com estranhamento e até com ar de deboche: "Quem é doido de querer mais filho? Uma hora a Bolsa acaba. E aí?"

Para finalizar, concluímos que a coexistência de políticas sociais e políticas agrícolas de fomento econômico têm repercussão altamente virtuosa no grupo sobre o qual orientamos as nossas reflexões. Em decorrência, contestamos a sugestão de abandono das políticas agrícolas para produtores de base familiar considerados "como economicamente irrelevantes" e sem chance para contribuir para o desenvolvimento do Brasil (ALVES e ROCHA, 2010; BUAINAIN et al., 2013). Contrasta com a compreensão dos autores a experiência das catadoras de mangaba que tinham, antes do PAA, uma renda estimada em $27 \%$ de um salário mínimo oriunda da venda do produto do extrativismo, e que, após o PAA, alcançam melhores condições de vida, explícita pela reforma das casas, aquisição de instrumentos de trabalho e recursos para alimentação e vestuário. O exemplo mostra que, com pouco investimento, as atividades econômicas desse grupo foram dinamizadas.

No contexto político da última década, o debate sobre o PBF tem sido desvendado como "um bom exemplo da repetição histórica do preconceito e da força dos estereótipos" (REGO e PINZANI, 2013a) contra os pobres. Em relação ao PAA, há sinalizações de que os seus afiliados reforçam as suas estratégias para além do campo econômico com a promoção de "práticas agrícolas diversificadas, adaptadas ao contexto ambiental em que se encontram, valorizadoras da diversidade regional, e promotoras de autonomia" (GRISA, 2014, p. 27). Como já apontaram vários estudos sobre o PAA, concomitante à produção agrícola, nesses casos, valoriza-se a diversidade na sua mais ampla acepção a partir das capacidades locais. Assim, como indica Delgado (2013, p. 6), o PAA se

credencia com um selo de legitimidade social da maior significação; ainda mais porque corroborado pela eficácia no plano fiscal - de realizar duas ações relevantes, de política agrícola e de política social, com o mesmo recurso orçamentário.

\section{Referências bibliográficas}

ALENCAR, E. F. As Mulheres pescadoras e a conservação de recursos pesqueiros na Reserva de Desenvolvimento Sustentável Mamirauá (AM). In: SCHERER, E. Trabalhadores e trabalhadoras na pesca: ambiente e reconhecimento. Rio de Janeiro: Garamond, 2013, p. 21-49.

ALVES, E. e ROCHA, D. de P. Ganhar tempo é possível?. In: GASQUES, J. G., VIEIRA FILHO, J. E. R. e NAVARRO, Z. (Org.). A agricultura brasileira: desempenho, desafios e perspectivas. Brasília, IPEA, 2010, p. 275-290.

BIANCO. B. F. Prefácio. In: ZHOURI, A. (Org.). Desenvolvimento, reconhecimento de direitos e conflitos territoriais. Brasília, DF: ABA, 2012, p. 7-10.

BRASIL. Ministério do Desenvolvimento Social e Combate à Fome. Relatórios de informações sociais. 
2014a. Disponível em: <http://aplicacoes.mds.gov.br/ sagi/RIv3/geral/relatorio.php\#Benef\%C3\%ADcios $>$. Acesso em: 20 jul. 2014.

Ministério do Desenvolvimento Social e Combate à Fome. Acompanhamento das famílias PBF no Sicon. 2014b Disponível em: <http://www.mds.gov.br/ bolsafamilia/capacitacao/resolveuid/40ac4976747efd0d 8625f352675507f4/download >. Acesso em: 20 jul. 2014.

Buainain, A. M., ALVES, E., SILVEIRA, J. M. e Navarro, Z.. Sete teses sobre o mundo rural brasileiro. Revista de Política Agrícola, Brasília, ano 22, n. 2, p. 105-121, jun. 2013.

CASTRO, E. Expansão da fronteira, mega projetos de infraestrutura e integração sul-americana. Caderno $\mathrm{CRH}$, v. 25, n. 64, p. 45-61, jan./abr. 2012.

CAVALCANTI, J. S. B., ANDRADE, B. B. F. de e RODRIGUES, V. Mulheres e trabalho na agricultura de exportação: questões atuais. Revista Anthropológicas, ano 16 , v. 23, n. 1, p. $67-88,2012$.

CONAB. Programa de Aquisição de Alimentos. 2014a. Disponível em: <http://www.agricultura.gov.br/arq editor/file/camaras_setoriais/Mandioca/29RO/App_ SUPAF_Mandioca.pdf $>$. Acesso em: 30 jul. 2014.

CONAB. Resultado das ações da Conab em 2013. Brasília, DF, 2013. 23 p.

CRUZ, A. T. Mulheres da floresta do Vale do Guaporé e suas interações com o ambiente. Estudos Feministas, v. 16, n. 3, p. 913-925, set./dez. 2010.

DE LA GARZA, E. T. Trabajo no clássico y flexibilidad. Caderno CRH: Revista do Centro de Recursos Humanos da UFBA, v. 26, n. 68, p. 315-330, 2013.

El papel del concepto de trabajo en la teoria social del siglo XX. In: DE LA GARZA, E. T. (Org.). Tratado Latinoamericano de Sociologia del Trabajo. México: Fondo de Cultura Económica, 2000, p. 15-35.

DELGADO, G. C. Pesquisa de avaliação de concepção e implementação do Programa Aquisição de Alimentos - PAA: relatório de avaliação do PAA (Síntese). Brasília, DF: Conab; PNUD, 2013. 17 p. Mimeografado.

ESMERALDO, G. G. S. L. O protagonismo político de mulheres rurais por seu reconhecimento econômico e social. In: NEVES, D. P. e MEDEIROS, L. S. de (Org.). Mulheres camponesas: trabalho produtivo e engajamentos políticos. Niterói: Alternativa, 2013, p. 237-256.

ESTERCI, N. Populações tradicionais. In: ALMANAQUE Brasil Socioambiental. São Paulo: ISA, 2007. p. 23-225.
FORTES, M. O ciclo de desenvolvimento do grupo doméstico. Brasília, DF: Universidade Federal de Brasília, 1974. p. 1-9.

GARCIA JUNIOR, A. e HEREDIA, B. Trabalho familiar e campesinato. América Latina, v. 14, n. 12, jan./jun. 1971. p. 10-19.

GRISA, C. A agricultura familiar nas políticas públicas em análise. Oficina de elaboração de artigos para publicação técnica no tema "Agricultura Familiar: atuais perspectivas e futuro". Brasília, DF: [s. n.], 2014. 33 p. Mimeografado.

HÉBETTE, J., ALVES, J. M. e QUINTELA, R. S. da. Parentesco, vizinhança e organização profissional na formação da fronteira amazônica. In: HÉBETTE, J., MAGALHÃES, S. B. e MANESCHY, M. C. (Org.). No mar, nos rios e na fronteira: faces do campesinato no Pará. Belém, PA: Edufpa, 2002. p. 175-202.

HEREDIA, B. M. A. de. A morada da vida: trabalho familiar de pequenos produtores do Nordeste do Brasil. Rio de Janeiro: Paz e Terra, 1979. 164 p. (Estudos sobre o Nordeste, v. 7).

LOURENÇO, C., HENKEL, J. A. e MANESCHY, M. C. A Seguridade social para os pescadores artesanais no Brasil: estudo de caso no Pará. Chennai: ICSF, 2006. v. 1.

MALDONADO, S. C. Pescadores do mar. São Paulo: Ática, 1986.78 p.

MANESCHY, M. C. Mulheres na pesca artesanal: trajetórias, identidades e papéis em um porto pesqueiro no litoral do estado do Pará. In: NEVES, D. P.; MEDEIROS, L. S. de (Org.). Mulheres camponesas: trabalho produtivo e engajamentos políticos. Niterói: Alternativa, 2013. p. 41-64.

MORAES, S. C. Colônias de pescadores e a luta pela cidadania. In: CONGRESSO BRASILEIRO DE SOCIOLOGIA, 10, 2001, Fortaleza. Sociedade e Cidadania: novas utopias - Programas e Resumos... Fortaleza: SBS, 2001. p. 91.

MOREIRA, H. C. L. e SCHERER, E. Os pescadores, o seguro defeso e a conservação ambiental no Amazonas. In: SCHERER, E. Trabalhadores e trabalhadoras na pesca: ambiente e reconhecimento. Rio de Janeiro: Garamond, 2013. p. 125-151.

MOTA, D. M. da. Trabalho e sociabilidade em espaços rurais. Fortaleza: Banco do Nordeste/ Embrapa Tabuleiros Costeiros, 2005. $241 \mathrm{p}$.

MOTA, D. M. da, SILVA JÚNIOR, J. F. da, SCHMITZ, H. e RODRIGUES, R. F. de A. A Mangabeira. As Catadoras. O Extrativismo. Belém, PA: Embrapa Amazônia Oriental; Aracaju: Embrapa Tabuleiros Costeiros, 2011. 297 p. 
NEVES, D. P. A perversão do trabalho infantil: lógicas sociais e alternativas de prevenção. Niterói: Intertexto, 1999. 241 p.

- e MEDEIROS, L. S. de. Apresentação da coletânea. In: NEVES, D. P. e MEDEIROS, L. S. de (Org.). Mulheres camponesas: trabalho produtivo e engajamentos políticos. Niterói: Alternativa, 2013. p. 13-16.

PAULILO, M. I. S. A inadequação das políticas públicas no aumento da satisfação e do bem-estar das mulheres rurais. In: WORLD CONGRESS OF RURAL SOCIOLOGY, 8., 2012, Lisboa. The New Rural World: From Crisis to Opportunities. Lisboa: IRSA: Universidade Técnica de Lisboa, 2012.

PEREIRA, E. O. Extrativismo da mangaba (Hancornia speciosa Gomes) no Povoado Alagamar, Pirambu - SE. 2008. 102 f. Dissertação (Mestrado em Agroecossistemas) - Universidade Federal de Sergipe, Núcleo de PósGraduação e Estudos em Recursos Naturais, São Cristóvão.

REGO, W. L. e PINZANI, A. Vozes do Bolsa Família: autonomia, dinheiro e cidadania. São Paulo: Editora Unesp, 2013a. 241 p.

REGO, W. D. L. e PINZANI, A. Liberdade, dinheiro e autonomia: o caso da Bolsa Família. Revista de Ciências Sociais, v. 38, p. 21-42, abr. 2013 b.

REIGADA, A. Um olhar feminista sobre o trabalho nas cadeias agrícolas globais. Revista Contemporânea, v. 4, n. 1, p. 19-41, jan./jun. 2014.

RIBEIRO, D. Ensaios insólitos. 2. ed. Rio de Janeiro: Ludens, 2011. 221 p.

SANTOS, J. V. O papel das mulheres na conservação das áreas de remanescentes de mangabeiras (Hancornia speciosa Gomes). 2007. 103 f. Dissertação (Mestrado em Agroecossistemas) - Universidade Federal de Sergipe, Núcleo de Pós-Graduação em Estudos e Recursos Naturais, São Cristovão.

SARMENTO, M. J. e STROPASOLAS, V. L. Os sentidos do trabalho infantil no campo. Travessias: Revista de
Ciências Sociais e Humanas em Lingua Portuguesa, n. 10, p. 233-263, 2010.

SCHERER, E. Trabalhadores e trabalhadoras na pesca: ambiente e reconhecimento. Rio de Janeiro: Garamond, 2013. 212 p.

SCHMITZ, H., MOTA, D. M. da e SILVA JÚNIOR, J. F. Gestão coletiva de bens comuns no extrativismo da mangaba no Nordeste do Brasil. Ambiente e Sociedade, v. 12, n .2, p. 273-292, jul./dez. 2009.

SCHMITZ, H., MOTA, D. M. da. e PEREIRA. J. A. G. Pescadores artesanais e seguro defeso: reflexões sobre processos de constituição de identidades numa comunidade ribeirinha da Amazônia. AmazônicaRevista de Antropologia, v. 5, p. 116-139. 2013.

SHIRAISHI NETO, J. Novos movimentos sociais e padrões jurídicos no processo de redefinição da região amazônica. In: SHIRAISHI NETO, J., LIMA, R. M., CARDOSO, L. F. C. e MESQUITA, B. A. de (Org.). Meio ambiente, território e práticas jurídicas: enredos em conflito. Manaus: EDUFMA, 2011. p. 23-52.

SILIPRANDI, E. e CINTRÃO, R. As mulheres agricultoras e sua participação no Programa de Aquisição de Alimentos (PAA). Segurança Alimentar e Nutricional, Campinas, v. 18, n. 2, p. 12-32, 2011. Disponível em: < http://www.unicamp. br/nepa/arquivo_san/volume_18_2_2011/nepa_cap2. pdf > . Acesso em: 28 nov. 2011.

SILVA, M. R. Povos da terra é água: a comunidade pesqueira Canto do Mangue, Canguaretama, RN - Brasil. Piracicaba: [s. n.], 2004. $126 \mathrm{p}$.

SIMONIAN, L. Mulheres, cultura e mudança nos castanhais do Sul do Amapá. In: Mulheres da floresta Amazônica: entre o trabalho e a cultura. Belém, PA: UFPA, NAEA, 2001. p. 107-148.

TEIXEIRA, G. S. e ABDALLAH, P. R. Política de segurodesemprego ao pescador artesanal: assistencialismo ou incentivo? In: CONGRESSO DA SOCIEDADE BRASILEIRA DE ECONOMIA, ADMINISTRAÇÃO E SOCIOLOGIA RURAL, 46., 2008, Rio Branco. Amazônia, mudanças globais e agronegócios: o desenvolvimento em questão. Brasília, DF: Sober; Rio Branco: UFAC, 2008. 